\title{
Notch signaling and non-small cell lung cancer (Review)
}

\author{
BIN ZOU*, XUE-LIANG ZHOU*, SONG-QING LAI and JI-CHUN LIU \\ Department of Cardiothoracic Surgery, First Affiliated Hospital, Nanchang University, Nanchang, Jiangxi 330006, P.R. China
}

Received March 15, 2016; Accepted October 19, 2017

DOI: $10.3892 / \mathrm{ol} .2018 .7738$

\begin{abstract}
Lung cancer is the leading cause of cancer-associated mortality worldwide. Elucidation of the pathogenesis and biology of lung cancer is critical for the design of an effective treatment for patients. Non-small cell lung cancer (NSCLC) accounts for $80-85 \%$ of lung cancer cases. The abnormal expression of Notch signaling pathway members is a relatively frequent event in NSCLC. The Notch signaling pathway serves important roles in cell fate determination, proliferation, differentiation and apoptosis. Increasing evidence supports the association of Notch signaling dysregulation with various types of malignant tumor, including NSCLC. Several studies have demonstrated that members of the Notch signaling pathway may be potential biomarkers for predicting the progression and prognosis of patients with NSCLC. Furthermore, Notch signaling serves critical roles in the tumorigenesis and treatment resistance of NSCLC cells by promoting the proliferation or inhibiting the apoptosis of NSCLC cells. The present review provides a detailed summary of the roles of Notch signaling in NSCLC.
\end{abstract}

\section{Contents}

1. Introduction

2. Expression and activation of Notch signaling in patients with NSCLC and its influence on disease progression and prognosis

3. Biological roles of Notch signaling in NSCLC

4. Conclusions

Correspondence to: Professor Ji-Chun Liu, Department of Cardiothoracic Surgery, First Affiliated Hospital, Nanchang University, 17 Yongwai Street, Donghu, Nanchang, Jiangxi 330006, P.R. China

E-mail: liujichun999@163.com

*Contributed equally

Key words: apoptosis, cancer stem cells, non-small cell lung cancer, Notch signaling, proliferation, resistance

\section{Introduction}

Lung cancer is one of the most common types of cancer worldwide; high morbidity and mortality rates are observed for all types of malignant lung tumor (1). Despite the extensive understanding of tumor biology, and advances in cancer diagnosis and treatment, the five-year survival rate of lung cancer improved by just 5\% during the past two decades (2). Non-small cell lung cancer (NSCLC) accounts for $80-85 \%$ of lung cancer cases (3). More than half of the patients (55\%) with NSCLC are diagnosed at an advanced stage of the disease (4), and the response rate to combination chemotherapy is only $20 \%$ (5). The lack of a system for early diagnosis or an effective treatment, tumor relapse and resistance to chemotherapy are the main problems in the diagnosis and treatment of NSCLC. Therefore, further understanding lung cancer biology, establishing an early detection system, searching for novel therapeutic targets and overcoming chemotherapy resistance are key to improving the prognosis of patients with NSCLC.

Notch signaling is a highly conserved evolutionary pathway. In mammals, the Notch signaling pathway consists of four Notch receptor isoforms (Notch1-4) and five ligands [Jagged1 and 2, delta-like ligand (DLL) 1, 3 and 4 (DLL4)] (6). Upon binding, the Notch receptor undergoes a series of proteolytic cleavages, resulting in the release of the Notch intracellular domain (NICD), which translocates to the nucleus and drives the expression of target genes, including Hes family BHLH transcription factor 1 (Hes 1) (7). Notch target genes serve important functions in cell fate determination, cell proliferation, differentiation, and apoptosis (8). Overwhelming data indicate that the abnormal expression of Notch has been identified in many types of malignant tumor, including NSCLC (9-12). The function of Notch as an oncogene or tumor suppressor depends on the cellular context (13). In this review, the expression and clinical value of Notch signaling in patients with NSCLC will be examined and the biological roles of Notch signaling in NSCLC cells will be detailed.

2. Expression and activation of Notch signaling in patients with NSCLC and its influence on disease progression and prognosis

The abnormal expression of Notch signaling pathway members, including Notch receptors, ligands and downstream genes, is a relatively frequently identified in NSCLC studies. Dang et al (10) indicated that the overexpression of Notch3 was identified in $40 \%$ of patients with NSCLC, and that this 
overexpression was associated with a translocation involving 19 p. Another previous study revealed that Notch3 was highly expressed in $51.1 \%$ of patients with NSCLC, which was significantly higher than its expression in adjacent noncancerous lung tissue (14). Gain-of-function mutations of Notch1 were present in $10 \%$ of patients with NSCLC, whereas the downregulation of Numb, a negative regulator of Notch, was observed in $30 \%$ of patients with NSCLC, resulting in increased Notch activity (15). One study indicated that the percentage of expression of Notch1 and Delta-like ligand 4 (DLL4) in lung squamous cell carcinoma (SCC) cells was significantly lower when compared with the other subtypes (16). In contrast, Li et al (17) identified that the percentage of expression of Notch1 protein in SCC was significantly higher than in adenocarcinomas (AC). These studies indicate that the expression of Notch signaling pathway members diverges in different histopathological types. However, the clinicopathological and prognostic roles of Notch signaling in NSCLC remain controversial. A number of studies have indicated that the overexpression of Notch1 is associated with tumor progression and poor prognosis in NSCLC $(14,16,18,19)$. However, other studies suggest that Notch1 and 3 may function as tumor suppressors $(17,20)$. In summary of these different studies, Yuan et al (21) performed a meta-analysis to evaluate the association of Notch signaling pathway members with the clinicopathological parameters and prognosis of patients with NSCLC (Table I). The study indicated that the overexpression of Notch1 and 3 was associated with a greater possibility of lymph node metastasis and reduced overall survival time in patients with NSCLC. Furthermore, the expression of Notch signaling ligand DLL4 and its target gene, Hes family bHLH transcription factor 1 (Hes1), were inversely associated with the overall survival rate in patients with NSCLC. The meta-analysis suggested that Notch signaling is a potential biomarker to predict the progression and prognosis of patients with NSCLC (20).

It is established that stromal cells within tumors serve important roles in the biology of cancer cells, including proliferation, apoptosis, migration and drug resistance $(22,23)$. The influence of the members of the Notch signaling pathway in stroma on tumor progression and prognosis has also been investigated (16) (Table I). The prognostic impact of measuring Notch signaling in stroma was evident in the study: The high expression of the members of the Notch signaling pathway predicted a better outcome for patients with NSCLC. It was therefore concluded to be likely that stromal Notch signaling inhibits cancer progression.

Although the results of the meta-analysis are relatively persuasive, certain questions remain to be answered. Firstly, only a limited number of patients were enrolled in the included studies, and the majority of the studies were retrospective. Multicenter prospective studies based on large, homogeneous patient populations are required to confirm the observations. Secondly, either immunohistochemistry or reverse transcription polymerase chain reaction were used to measure the expression of Notch signaling pathway members in the studies. Furthermore, the scoring system and cut-off values varied between studies, which may have subjectively influenced the final results. Also, tumor heterogeneity may have contributed to the inconsistent results of clinical studies.
The expression of Notch signaling and its clinical value differ in different histopathological types of NSCLC. A study has investigated the expression of Notch1 and its clinical significance in patients with different histological subtypes of lung AC (24). The study demonstrated that the overexpression of Notch1 was often observed in papillary predominant $\mathrm{AC}$ and micropapillary predominant AC tissues, whereas the negative expression of Notch1 was often presented in solid predominant AC tissues. This suggests that the expression and function of Notch1 are distinct in different phases of tumor development.

It is possible that the expression of Notch receptors and ligands fails to precisely reflect the activity of Notch signaling. Expression of the NICD and Notch target genes may more representatively reflect the activity of Notch signaling. The studies with this focus are limited in number. However, Westhoff et al (15) demonstrated that intermediate/high levels of activated Notch1 were observed in $26 \%$ of patients with NSCLC. There was a significant association between Notch activation and a relatively poor prognosis in patients with p53 mutations (Table I). A recent clinical study demonstrated that Notch1 serves distinct roles depending on its activation status in patients with NSCLC (25). Detectable tumor Notch1 was observed in $50 \%$ of cases, and was negatively associated with an advanced stage and nodal status. In contrast, activated Notch1 was identified in $12 \%$ of NSCLC patients, and was not significantly associated with stage or nodal status. These results suggest that future studies should also focus on the activation status of Notch signaling and its function in patients with NSCLC.

\section{Biological roles of Notch signaling in NSCLC}

Notch signaling in the tumorigenesis of NSCLC cells. Several studies have reported that Notch signaling is involved in the tumorigenesis of NSCLC cells. Using an inducible LSL-KRAS ${ }^{\mathrm{G} 12 \mathrm{D}}$ in vivo model of lung cancer, Osanyingbemi-Obidi et al (26) observed a transient upregulation of Notch pathway activity (Hes1) in early tumor precursor lesions. Further study revealed that the inhibition of Notch signaling by dominant-negative Mastermind-like (DNMAML) expression in vivo did not suppress cellular transformation or tumor growth in this model. It is possible that individual Notch isoforms have opposing effects on lung oncogenesis, whereas DNMAML expression inhibits Notch signaling (26). Therefore, more rigorous experiments are necessary.

Using the same mouse model, Maraver et al (27) demonstrated that the Notch pathway was hyperactive in murine $\mathrm{KRAS}^{\mathrm{G} 12 \mathrm{~V}}$-driven NSCLC, and that loss-of-function in the Notch pathway completely prevented the formation of NSCLC. These results provide indirect evidence that Notch signaling serves an important role in the tumorigenesis of NSCLC cells. However, the exact members of the Notch signaling pathway that function in tumorigenesis are unknown. One study explored the oncogenic potential of activated Notch1 using a DOX-inducible system, in which activated Notch1 was overexpressed in the alveolar epithelium (28). After 7 days of Notch1 induction, the transgenic mice developed alveolar hyperplasia, followed by apoptosis. After 8 months of induction, however, the mice developed pulmonary adenomas. The 
Table I. Clinicopathological and prognostic impacts of Notch signaling pathway members in patients with NSCLC.

\begin{tabular}{|c|c|c|c|c|c|c|}
\hline \multirow[b]{2}{*}{$\begin{array}{l}\text { Notch pathway } \\
\text { member }\end{array}$} & \multicolumn{2}{|c|}{ Clinicopathological parameters } & \multicolumn{3}{|c|}{ Prognosis } & \multirow[b]{2}{*}{ (Refs.) } \\
\hline & Tumor size & $\begin{array}{l}\text { Lymph node } \\
\text { metastasis }\end{array}$ & NSCLC & Adenocarcinoma & $\begin{array}{l}\text { Squamous cell } \\
\text { carcinoma }\end{array}$ & \\
\hline Notch1 & & $\mathrm{N}^{\mathrm{a}}$ & $\mathrm{OS}^{\mathrm{b}}$ & NS & NS & $(21)$ \\
\hline Notch3 & NS & $\mathrm{N}^{\mathrm{a}}$ & $\mathrm{OS}^{\mathrm{b}}$ & $\mathrm{OS}^{\mathrm{b}}$ & NS & $(21)$ \\
\hline DLL4 & & & $\mathrm{OS}^{\mathrm{b}}$ & $\mathrm{OS}^{\mathrm{b}}$ & $\mathrm{OS}^{\mathrm{b}}$ & $(21)$ \\
\hline DLL1 & & & NS & & & $(21)$ \\
\hline DLL3 & & & NS & & & $(21)$ \\
\hline Hes1 & & & $\mathrm{OS}^{\mathrm{b}}$ & $\mathrm{OS}^{\mathrm{b}}$ & $\mathrm{OS}^{\mathrm{b}}$ & $(21)$ \\
\hline Notch4 & NS & & 5-year SR ${ }^{b}$ & NS & NS & $(16)$ \\
\hline Stromal Notch4 & NS & $\mathrm{N}^{\mathrm{b}}$ & 5-year SR ${ }^{a}$ & NS & 5-year SR & $(16)$ \\
\hline Jagged 1 & NS & & NS & NS & NS & $(16)$ \\
\hline Stromal Jagged1 & NS & & 5-year SR ${ }^{a}$ & NS & 5-year SR ${ }^{a}$ & $(16)$ \\
\hline Stromal DLL4 & NS & & 5-year SR ${ }^{a}$ & NS & 5-year $\mathrm{SR}^{\mathrm{a}}$ & (16) \\
\hline Activated Notch 1 & & & $\begin{array}{l}\text { 5-year SR } \\
\text { (p53-negative group) }^{\mathrm{b}}\end{array}$ & & & (15) \\
\hline
\end{tabular}

aPositively associated; bnegatively associated. N, lymph node; NSCLC, non-small cell lung carcinoma; NS, not significant; OS, overall survival rate; DLL, delta-like ligand; Hes1, Hes family BHLH transcription factor 1; SR, survival rate.

mice engineered to co-express activated Notch1 and MYC developed lung ACs. Through Notch1 ablation in vivo, one study observed a marked decrease in tumor initiation and burden in an autochthonous mouse model of lung AC, demonstrating that Notch1 function is imperative for Kras-induced lung AC (29). Importantly, this study also revealed that Notch1 function is required for tumor initiation via the suppression of p53-mediated apoptosis. More recently, one study investigated the effects of conditional Notch1 and 2 receptor deletion on the tumorigenesis of NSCLC (30). Notch1 deficiency led to decreased early tumor formation compared with the controls, whereas Notch 2 deletion resulted in markedly increased tumor formation. Thus, the study suggests that Notch1 promotes tumor initiation as an oncogene, whereas Notch2 has tumor suppressor functions during lung tumorigenesis.

In conclusion, these studies provide strong evidence that Notch signaling serves a critical role in tumorigenesis of NSCLC. However, individual Notch isoforms may have distinct or even opposite effects on NSCLC tumorigenesis (Fig. 1). This suggests that the specific inhibition of different Notch molecules should be considered when devising a therapeutic approach, at least in the context of NSCLC. The tumorigenic role of other components of Notch signaling and their mechanisms also require elucidation.

Notch signaling in the proliferation and apoptosis of NSCLC cells. A number of studies have explored the function of Notch signaling in the proliferation and apoptosis of NSCLC cells. Chen et al (31) demonstrated that the overexpression of Notch1 Intracellular Domain (N1ICD) in AC cells inhibited cell growth and induced apoptosis. A recent study evaluated these effects of Notch signaling in different lung cancer cell lines; it was observed that the influence of Notch1 on proliferation and apoptosis depended on the cell type (32). The knockdown of
Notch1 resulted in increased cell proliferation and enhanced apoptosis, whereas its induction inhibited the growth of small cell lung cancer cells. Although Notch1 knockdown increased cell proliferation and inhibited apoptosis in A549 lung AC cells, it had no effect in SCC cells (31).

A number of studies have reported that the indirect inhibition of Notch1 in NSCLC cells resulted in decreased cell proliferation and the induction of apoptosis. For instance, $\delta$-tocotrienol inhibits cancer cell proliferation, induces apoptosis and reduces cancer cell invasion at least in part through the downregulation of Notch1 $(33,34)$. In hypoxic conditions, Notch1 was markedly elevated in lung AC cell lines, and the inhibition of Notch signaling via $\gamma$-secretase inhibitor induced apoptosis, which could be rescued by the reintroduction of active Notch1 (31). These data indicate that Notch1 may be essential for cell survival in hypoxia. Further studies have demonstrated that Notch1 stimulated NSCLC tumor growth and survival through the direct upregulation of insulin-like growth factor 1 receptor (IGF-1R) (35) and survivin (36) in hypoxia. One study revealed that the proliferation of NSCLC cells was significantly suppressed in vitro and in vivo when co-cultured with DLL4-expressing endothelial cells (37). Furthermore, silencing endothelial DLL4 or Notch1 significantly attenuated the effects of DLL4 on NSCLC cells. Phosphate and tensin homolog (PTEN) expression was increased by the introduction of endothelial cell-DLL4 or recombinant human-DLL4 protein, and was attenuated by Notch1 interference. These results suggest that the inhibitory effect of endothelial cells on NSCLC cells was via the DLL4/Notch1/PTEN signaling pathway (36). Taken together, these studies indicate that the biological outcome of Notch signaling in NSCLC cells was highly dependent on the cell type and context (Fig. 1). Therefore, the tumor microenvironment should also be considered when developing a therapeutic strategy. Organoid culture 


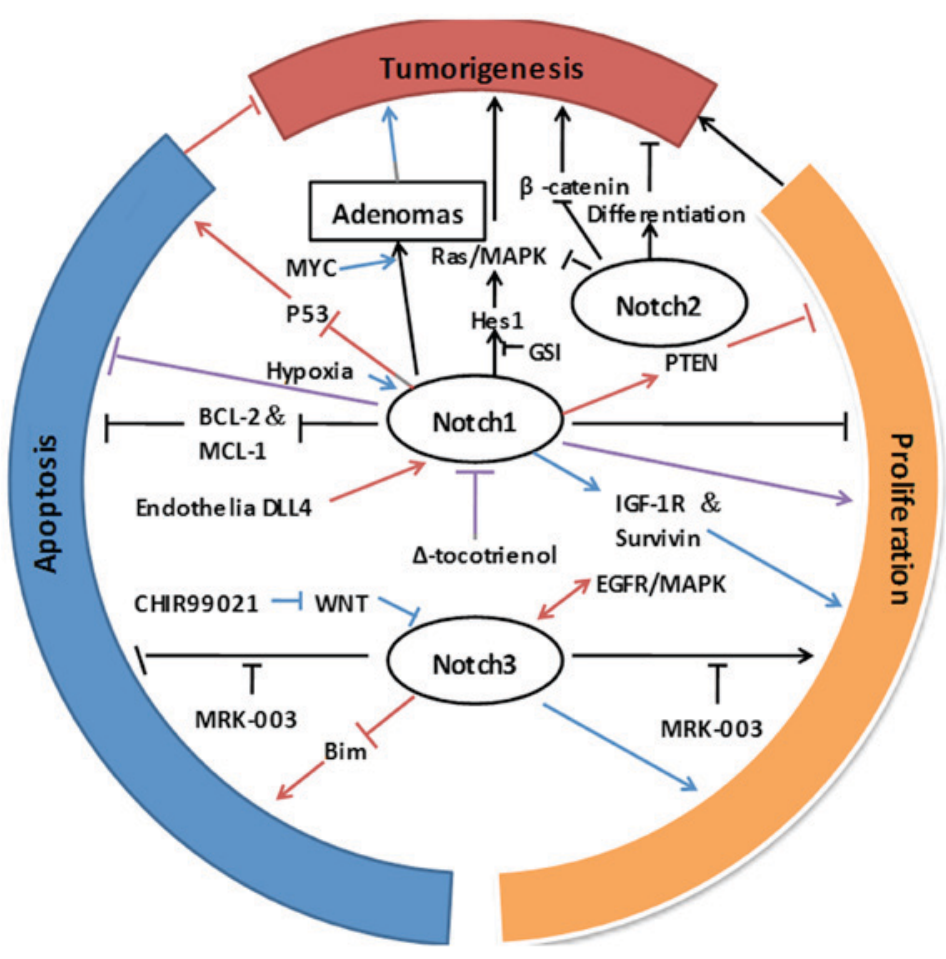

Figure 1. Roles of Notch signaling in tumorigenesis, proliferation, and apoptosis of NSCLC cells. Notch1 promotes tumor initiation as an oncogene, whereas Notch 2 exhibits tumor suppressor functions during lung carcinogenesis. Roles of Notch1 in cell proliferation and apoptosis are highly dependent on the cellular context. Overexpression of Notch1 in adenocarcinoma cells inhibited cell growth and induced apoptosis. Indirect inhibition of Notch1 resulted in decreased cell proliferation and induction of apoptosis. Notch1 stimulated NSCLC tumor growth and survival through direct upregulation of IGF-1R and survivin in hypoxia. Notch3 promoted cell proliferation and inhibited apoptosis of NSCLC cells. Inhibition of Notch3 activation represents a potential novel approach for the targeted therapy of NSCLC. Arrows present differing functions of Notch depending on cellular context. NSCLC, non-small cell lung cancer; IGF-1R, insulin-like growth factor 1 receptor; Bcl-2, B-cell lymphoma 2; MAPK, mitogen-activated protein kinase; PTEN, phosphatase and tensin homolog; Hes1, Hes family BHLH transcription factor 1; GSI, $\gamma$-secretase inhibitor; EGFR, epithelial growth factor receptor; MRK-003, GSI; Bim, Bcl-2 interacting mediator of cell death; DLL4, delta-like ligand 4; MCL-1, induced myeloid leukemia cell differentiation protein; p53, tumor protein 53.

in vitro and xenografts in vivo may be helpful in understanding the definite roles of Notch signaling in the proliferation and apoptosis of NSCLC cells.

The inhibition of Notch3 using dominant negative Notch3, $\gamma$-secretase inhibitor MRK-003 or specific Notch3 peptides results in growth suppression and the induction of apoptosis of lung cancer cells in vitro and in vivo (38-40). These results provide indirect evidence that Notch3 is involved in the proliferation and apoptosis of lung cancer cells. Further study demonstrated that Notch3 co-operated with the epidermal growth factor receptor (EGFR)-mitogen-activated protein kinase pathway to inhibit apoptosis through the inhibition of the pro-apoptotic protein, Bcl-2 interacting mediator of cell death (Bim), suggesting there is significant cross-talk between the two pathways (41). A recent study revealed the cross-talk between Wnt and Notch3 signaling pathways in the regulation of proliferation and apoptosis in NSCLC cell lines (42). The inhibition of Wnt signaling by CHIR99021 resulted in the upregulation of Notch3 protein and its downstream genes, Hes1 and Hes related family BHLH transcription factor with YRPW motif 1. CHIR99021 and Notch3 synergistically promoted the proliferation of NSCLC cells, and Notch3-short hairpin RNA (shRNA) significantly attenuated the positive effects of CHIR99021 on cell proliferation. Furthermore, Notch3-shRNA induced apoptosis and significantly weakened the inhibitory effect of CHIR99021 on apoptosis in H460 cells. These results support the hypothesis that the inhibition of Notcth3 activation represents a potential new approach for the targeted therapy of NSCLC (Fig. 1).

Notch signaling and chemotherapy/radiation resistance. Chemotherapy and radiation therapy are typically used to treat NSCLC tumors via the inhibition of cancer cell proliferation or the induction of apoptosis. Notch signaling may influence the response of tumor cells to chemotherapy and radiation therapy. The acquired resistance to conventional chemotherapy or targeted therapy is common in patients with NSCLC who initially respond to treatment. Low-dose cisplatin treatment can induce doxorubicin and paclitaxel tolerance, and the enrichment of CD133(+) cells, in lung AC cell lines (43). Another study demonstrated an evident weakening of this effect by treatment with a $\gamma$-secretase inhibitor (GSI) or Notch1 shRNAs (44). These results suggest that Notch signaling was implicated in the cisplatin-induced enrichment of CD133(+) cells and multidrug resistance.

One study explored the mechanism of acquired resistance to EGFR tyrosine kinase inhibitors in NSCLC tumors harboring an EGFR exon19 deletion (45). It was observed that the expression of Notch1 was highly upregulated in gefitinib-resistant PC9 lung cancer cells and that the activation of Notch1 resulted in an epithelial-mesenchymal transition (EMT) phenotype. Additionally, Notch1 knockdown reversed the EMT phenotype and restored sensitivity to gefitinib in gefitinib-resistant PC9 lung cancer cells. Further in vivo 
experimentation demonstrated that the inhibition of Notch signaling resulted in tumor growth retardation in $\mathrm{Balb} / \mathrm{cathymic}$ $(\mathrm{nu}+\mathrm{nu}+)$ mice with acquired resistant lung cancer xenografts. These results provide evidence that gefitinib-acquired resistance in lung cancer cells undergoing EMT depends on the activation of Notch1 signaling. The molecular mechanism of Notch-induced EMT in NSCLC was comprehensively analyzed by Yuan et al (46). In addition to its association with the acquired resistance to chemotherapy or targeted therapy, Notch signaling may be involved in primary resistance. A clinical study has indicated that Notch3 expression was negatively associated with the sensitivity to platinum-based chemotherapy in patients with NSCLC. The clinical evidence suggests that Notch3 was involved in chemotherapy resistance and could act as a biomarker to predict the chemotherapy response and prognosis of patients with NSCLC (47).

Previous research provides evidence that Notch signaling may also be involved in radiation resistance (48). In this study, Notch1 or 3 was activated subsequent to radiation treatment, depending on the cell type. Radiation followed by GSI treatment conferred a greater suppressive effect on lung cancer cells in vitro and in vivo compared with other treatments. The activation of Notch signaling by radiation contributed to radiation resistance and the inhibition of Notch signaling restored the sensitivity of cancer cells to radiation. Radiation treatment induced Notch1 expression and promoted EMT in NSCLC cells. This could be inhibited by rhamnetin and cirsiliol, resulting in the recovery of radiosensitization (49). Theys et al (50) demonstrated that Notch activity had no effect on the radiation sensitivity of $\mathrm{H} 460$ cells in vitro, although high Notch1 activity promoted tumor growth and induced radiation resistance in vivo. It is possible that the role of Notch signaling in vitro does not represent the behaviors of cancer cells in vivo. Taken together, these results suggest that Notch signaling serves important roles in radiation resistance and that the inhibition of Notch signaling may be a promising approach to improve the outcome of patients with NSCLC undergoing radiotherapy. These findings further support the hypothesis that the biological outcome of Notch signaling in NSCLC cells is highly dependent on the cell type and context.

Notch signaling appears to be essential for cancer cell survival, particularly as a response to specific microenvironment conditions or stress. Therefore, Notch inhibition in combination with chemotherapy or radiation may achieve an improved therapeutic outcome compared with that with a single treatment. Notch inhibitors are typically GSIs, short interfering RNA or monoclonal antibodies against Notch receptors or ligands (51). GSIs are the most extensively explored in clinical trials and were reviewed by Yuan et al (52). It was concluded that the combination of chemotherapy or radiotherapy with GSIs had a synergistic effect, and holds promise for cancer control.

Notch signaling and lung cancer stem cells. Tumors comprise a heterogeneous population of cells (53). A rare subpopulation of tumor cells possesses stem cell-like properties and behaviors of self-renewal, multi-potential differentiation, tumor initiation and propagation. This population was, therefore, termed cancer stem cells (CSCs) (54). CSCs have been identified in human acute myeloid leukemia and in solid tumors, including breast, brain, prostate, colon, pancreatic and lung cancers (55-61). CSCs are dormant, and resistant to radiation and chemotherapy $(62,63)$. Lung CSCs contribute to tumor growth, invasion and metastases $(64,65)$. The concept of CSCs may provide an explanation for tumor behaviors including recurrence, metastases and therapeutic resistance. Therefore, targeting CSCs may be a promising approach for the eradication of lung cancer cells.

The source, maintenance and molecular markers of CSCs remain incompletely characterized. A previous study supports the hypothesis that cancer stem cells are derived from normal stem cells following oncogenic transformation (66). Another hypothesis states that malignant progenitor cells or differentiated cells can be induced to acquire stem cell properties through additional gene activation or mutation $(67,68)$. The role of Notch signaling in lung CSCs has been explored by a number of studies. Aldehyde dehydrogenase (ALDH) is an established marker for lung CSCs (61). ALDH ${ }^{+}$lung cancer cells are capable of self-renewal and possess a highly tumorigenic and clonogenic ability compared with their $\mathrm{ALDH}^{-}$counterparts. Higher activity of Notch signaling was observed in $\mathrm{ALDH}^{+}$lung cancer cells than in the $\mathrm{ALDH}^{-}$ subpopulation, and the inhibition of the Notch pathway resulted in a significant decrease in the proportion of $\mathrm{ALDH}^{+}$ lung cancer cells. These results suggest that Notch signaling serves a role in the maintenance of lung CSCs (69). Using a lentiviral Notch reporter vector and flow cytometry, lung AC cells can be divided into subpopulations of green fluorescent protein (GFP)-bright and GFP-dim cells (70). GFP-bright cells exhibit the stem cell properties of self-renewal, multi-potency, continuous tumorigenic ability and chemotherapy resistance in vivo. Zheng et al (71) identified CD24+ITGB4+Notch ${ }^{\text {hi }}$ cells as tumor-propagating cells, which have an increased ability to self-renew and propagate in vitro and in vivo. GSI treatment or Notch3 knockdown decreased self-renewal and tumor propagation in NSCLC cell lines and patient primary tumors. This suggests an important role of Notch3 in the self-renewal and propagation of NSCLC cells. These studies provide strong evidence that Notch signaling serves an important role in lung CSCs and that the inhibition of Notch signaling may be a promising way to target lung CSCs.

\section{Conclusions}

The abnormal expression of Notch signaling pathway members is a relatively frequent event in patients with NSCLC $(9,13-16)$. Although the clinicopathological and prognostic value of Notch signaling in NSCLC remains controversial, the meta-analysis by Yuan et al (21) revealed that a number of Notch molecules and their ligands were associated with lymph node metastasis and could act as biomarkers to predict the prognosis of patients. Further large-scale analyses are required to clarify the clinical value of members of the Notch signaling pathway in different populations.

Although the study by Osanyingbemi-Obidi et al (26) with a transgenic mouse model provides strong evidence that Notch signaling serves a critical role in the tumorigenesis of NSCLC cells, individual Notch isoforms may have opposing effects. Based on the conclusions of the previously described studies, Notch1 promotes tumor growth as an 
oncogene, whereas Notch2 exhibits tumor suppressor functions, suggesting that Notch-targeted therapies should be used prudently until Notch signaling in NSCLC is completely characterized. Further studies are required to understand the tumorigenic roles of the other components of Notch signaling and their molecular mechanisms. The influence of Notch signaling on proliferation and apoptosis depends on the cell type and microenvironment. Therefore, the cell type and context should be taken into consideration when studying the biological influence of Notch signaling in NSCLC. Notch signaling is activated by chemotherapy and radiation treatment in NSCLC cells, and may be essential for survival under stress, as well as causing cells to become more resistant. Although the mechanism underlying the development of lung CSCs is not entirely clear, it is likely that Notch signaling serves an important role in the maintenance of lung CSCs. Taken together, Notch signaling is associated with the tumorigenesis, progression and therapeutic resistance of NSCLC; therefore, targeting Notch signaling has the potential to improve the outcome for patients with NSCLC.

\section{Acknowledgements}

The present study was supported in part by grants from the National Natural Science Foundation of China (grant no. 81260024), the Natural Science Foundation of China (grant no. 81460065) and the Graduate Innovation Fund of Jiangxi Province (grant no. YC2015-B009).

\section{References}

1. Torre LA, Bray F, Siegel RL, Ferlay J, Lortet-Tieulent J and Jemal A: Global cancer statistics, 2012. CA Cancer J Clin 65: $87-108,2015$

2. Johnson DH, Schiller JH and Bunn PA Jr: Recent clinical advances in lung cancer management. J Clin Oncol 32: 973-982, 2014.

3. Parkin DM: Global cancer statistics in the year 2000. Lancet Oncol 2: 533-543, 2001.

4. Howlader N NA, Krapcho M, Garshell J, Miller D, Altekruse SF, Kosary CL, Yu M, Ruhl J, Tatalovich Z, Mariotto A, et al: (eds): SEER cancer statistics review, 1975-2012. National Cancer Institute, Bethesda MD, 2015.

5. Schiller JH, Harrington D, Belani CP, Langer C, Sandler A, Krook J, Zhu J and Johnson DH; Eastern Cooperative Oncology Group: Comparison of four chemotherapy regimens for advanced non-small-cell lung cancer. N Engl J Med 346: 92-98, 2002.

6. Fleming RJ: Structural conservation of Notch receptors and ligands. Semin Cell Dev Biol 9: 599-607, 1998.

7. Kageyama R and Ohtsuka T: The Notch-Hes pathway in mammalian neural development. Cell Res 9: 179-188, 1999.

8. Hori K, Sen A and Artavanis-Tsakonas S: Notch signaling at a glance. J Cell Sci 126: 2135-2140, 2013.

9. Zagouras P, Stifani S, Blaumueller CM, Carcangiu ML and Artavanis-Tsakonas S: Alterations in Notch signaling in neoplastic lesions of the human cervix. Proc Natl Acad Sci USA 92: 6414-6418, 1995.

10. Dang TP, Gazdar AF, Virmani AK, Sepetavec T, Hande KR Minna JD, Roberts JR and Carbone DP: Chromosome 19 translocation, overexpression of Notch3, and human lung cancer. J Natl Cancer Inst 92: 1355-1357, 2000.

11. Santagata S, Demichelis F, Riva A, Varambally S, Hofer MD, Kutok JL, Kim R, Tang J, Montie JE, Chinnaiyan AM, et al: JAGGED1 expression is associated with prostate cancer metastasis and recurrence. Cancer Res 64: 6854-6857, 2004.

12. Grabher C, von Boehmer $\mathrm{H}$ and Look AT: Notch 1 activation in the molecular pathogenesis of T-cell acute lymphoblastic leukaemia. Nat Rev Cancer 6: 347-359, 2006.

13. Roy M, Pear WS and Aster JC: The multifaceted role of Notch in cancer. Curr Opin Genet Dev 17: 52-59, 2007.
14. Ye YZ, Zhang ZH, Fan XY, Xu XL, Chen ML, Chang BW and Zhang YB: Notch3 overexpression associates with poor prognosis in human non-small-cell lung cancer. Med Oncol 30: 595, 2013.

15. Westhoff B, Colaluca IN, D'Ario G, Donzelli M, Tosoni D, Volorio S, Pelosi G, Spaggiari L, Mazzarol G, Viale G, et al: Alterations of the Notch pathway in lung cancer. Proc Natl Acad Sci USA 106: 22293-22298, 2009.

16. Donnem T, Andersen S, Al-Shibli K, Al-Saad S, Busund LT and Bremnes RM: Prognostic impact of Notch ligands and receptors in nonsmall cell lung cancer: Coexpression of Notch-1 and vascular endothelial growth factor-A predicts poor survival. Cancer 116: 5676-5685, 2010.

17. Li Y, Burns JA, Cheney CA, Zhang N, Vitelli S, Wang F, Bett A, Chastain M, Audoly LP and Zhang ZQ: Distinct expression profiles of Notch-1 protein in human solid tumors: Implications for development of targeted therapeutic monoclonal antibodies. Biologics 4: 163-171, 2010.

18. Andersen S, Donnem T, Al-Saad S, Al-Shibli K, Stenvold H, Busund LT and Bremnes RM: Correlation and coexpression of HIFs and NOTCH markers in NSCLC. Anticancer Res 31: 1603-1606, 2011.

19. Okayama H, Kohno T, Ishii Y, Shimada Y, Shiraishi K, Iwakawa R, Furuta K, Tsuta K, Shibata T, Yamamoto S, et al: Identification of genes upregulated in ALK-positive and EGFR/KRAS/ALK-negative lung adenocarcinomas. Cancer Res 72: 100-111, 2012.

20. Lee SM, Jung CK, Ko YH, Choi JY, Lee KY and Kang CS: Expression of Notch 1 and 3 is related to inhibition of lymph node metastasis and progression in non-small cell lung carcinomas. Basic Appl Pathol 1: 93-97, 2008.

21. Yuan X, Wu H, Xu H, Han N, Chu Q, Yu S, Chen Y and Wu K: Meta-analysis reveals the correlation of Notch signaling with non-small cell lung cancer progression and prognosis. Sci Rep 5: $10338,2015$.

22. Hanahan D and Weinberg RA: Hallmarks of cancer: The next generation. Cell 144: 646-674, 2011.

23. Liu R, Wei S, Chen J and Xu S: Mesenchymal stem cells in lung cancer tumor microenvironment: Their biological properties, influence on tumor growth and therapeutic implications. Cancer Lett 353: 145-152, 2014.

24. Huang J, Song H, Liu B, Yu B, Wang R and Chen L: Expression of Notch-1 and its clinical significance in different histological subtypes of human lung adenocarcinoma. J Exp Clin Cancer Res 32: 84, 2013

25. Nguyen D, Rubinstein L, Takebe N, Miele L, Tomaszewski JE, Ivy P, Doroshow JH and Yang SX: Notch1 phenotype and clinical stage progression in non-small cell lung cancer. J Hematol Oncol 8: 9, 2015

26. Osanyingbemi-Obidi J, Dobromilskaya I, Illei PB, Hann CL and Rudin CM: Notch signaling contributes to lung cancer clonogenic capacity in vitro but may be circumvented in tumorigenesis in vivo. Mol Cancer Res 9: 1746-1754, 2011.

27. Maraver A, Fernández-Marcos PJ, Herranz D, Muñoz-Martin M, Gomez-Lopez G, Cañamero M, Mulero F, Megías D, SanchezCarbayo M, Shen J, et al: Therapeutic effect of $\gamma$-secretase inhibition in KrasG12V-driven non-small cell lung carcinoma by derepression of DUSP1 and inhibition of ERK. Cancer Cell 22: 222-234, 2012.

28. Allen TD, Rodriguez EM, Jones KD and Bishop JM: Activated Notch1 induces lung adenomas in mice and cooperates with Myc in the generation of lung adenocarcinoma. Cancer Res 71: 6010-6018, 2011.

29. Licciulli S, Avila JL, Hanlon L, Troutman S, Cesaroni M, Kota S, Keith B, Simon MC, Puré E, Radtke F, et al: Notch1 is required for Kras-induced lung adenocarcinoma and controls tumor cell survival via p53. Cancer Res 73: 5974-5984, 2013.

30. Baumgart A, Mazur PK, Anton M, Rudelius M, Schwamborn K, Feuchtinger A, Behnke K, Walch A, Braren R, Peschel C, et al: Opposing role of Notch1 and Notch2 in a Kras(G12D)-driven murine non-small cell lung cancer model. Oncogene 34: 578-588, 2015.

31. Chen Y, De Marco MA, Graziani I, Gazdar AF, Strack PR, Miele L and Bocchetta M: Oxygen concentration determines the biological effects of NOTCH-1 signaling in adenocarcinoma of the lung. Cancer Res 67: 7954-7959, 2007.

32. Wael H, Yoshida R, Kudoh S, Hasegawa K, Niimori-Kita K and Ito T: Notch1 signaling controls cell proliferation, apoptosis and differentiation in lung carcinoma. Lung Cancer 85: 131-140, 2014. 
33. Ji X, Wang Z, Geamanu A, Sarkar FH and Gupta SV: Inhibition of cell growth and induction of apoptosis in non-small cell lung cancer cells by delta-tocotrienol is associated with notch-1 down-regulation. J Cell Biochem 112: 2773-2783, 2011.

34. Ji X, Wang Z, Geamanu A, Goja A, Sarkar FH and Gupta SV: Delta-tocotrienol suppresses Notch-1 pathway by upregulating miR-34a in nonsmall cell lung cancer cells. Int J Cancer 131: 2668-2677, 2012.

35. Eliasz S, Liang SY, De Marco MA, Machek O, Skucha S, Miele L and Bocchetta M: Notch1 stimulates survival of lung adenocarcinoma cells during hypoxia by activating the IGF-1R pathway. Oncogene 29: 2488-2498, 2010.

36. Chen Y, Li D, Liu H, Xu H, Zheng H, Qian F, Li W, Zhao C, Wang $\mathrm{Z}$ and Wang $\mathrm{X}$ : Notch-1 signaling facilitates survivin expression in human non-small cell lung cancer cells. Cancer Biol Ther 11: 14-21, 2011.

37. Ding XY, Ding J, Wu K, Wen W, Liu C, Yan HX, Chen C, Wang S, Tang H, Gao CK, et al: Cross-talk between endothelial cells and tumor via delta-like ligand 4/Notch/PTEN signaling inhibits lung cancer growth. Oncogene 31: 2899-2906, 2012.

38. Haruki N, Kawaguchi KS, Eichenberger S, Massion PP, Olson S, Gonzalez A, Carbone DP and Dang TP: Dominant-negative Notch3 receptor inhibits mitogen-activated protein kinase pathway and the growth of human lung cancers. Cancer Res 65: 3555-3561, 2005 .

39. Konishi J, Kawaguchi KS, Vo H, Haruki N, Gonzalez A, Carbone DP and Dang TP: Gamma-secretase inhibitor prevents Notch 3 activation and reduces proliferation in human lung cancers. Cancer Res 67: 8051-8057, 2007.

40. Lin L, Mernaugh R, Yi F, Blum D, Carbone DP and Dang TP: Targeting specific regions of the Notch3 ligand-binding domain induces apoptosis and inhibits tumor growth in lung cancer. Cancer Res 70: 632-638, 2010.

41. Konishi J, Yi F, Chen X, Vo H, Carbone DP and Dang TP: Notch3 cooperates with the EGFR pathway to modulate apoptosis through the induction of bim. Oncogene 29: 589-596, 2010.

42. Li C, Zhang S, Lu Y, Zhang Y, Wang E and Cui Z: The roles of Notch3 on the cell proliferation and apoptosis induced by CHIR99021 in NSCLC cell lines: A functional link between Wnt and Notch signaling pathways. PLoS One 8: e84659, 2013.

43. Salnikov AV, Gladkich J, Moldenhauer G, Volm M, Mattern J and Herr I: CD133 is indicative for a resistance phenotype but does not represent a prognostic marker for survival of non-small cell lung cancer patients. Int J Cancer 126: 950-958, 2010.

44. Liu YP, Yang CJ, Huang MS, Yeh CT, Wu AT, Lee YC, Lai TC, Lee CH, Hsiao YW, Lu J, et al: Cisplatin selects for multidrug-resistant CD133+ cells in lung adenocarcinoma by activating Notch signaling. Cancer Res 73: 406-416, 2013.

45. Xie M, He CS, Wei SH and Zhang L: Notch-1 contributes to epidermal growth factor receptor tyrosine kinase inhibitor acquired resistance in non-small cell lung cancer in vitro and in vivo. Eur J Cancer 49: 3559-3572, 2013.

46. Yuan X, Wu H, Han N, Xu H, Chu Q, Yu S, Chen Y and Wu K: Notch signaling and EMT in non-small cell lung cancer: Biological significance and therapeutic application. J Hematol Oncol 7: 87, 2014.

47. Shi C, Qian J, Ma M, Zhang Y and Han B: Notch 3 Protein, not its gene polymorphism, is associated with the chemotherapy response and prognosis of advanced NSCLC patients. Cell Physiol Biochem 34: 743-752, 2014

48. MizugakiH,Sakakibara-Konishi J,Ikezawa Y,Kikuchi J,KikuchiE, Oizumi S, Dang TP and Nishimura M: $\gamma$-Secretase inhibitor enhances antitumour effect of radiation in Notch-expressing lung cancer. Br J Cancer 106: 1953-1959, 2012.

49. Kang J, Kim E, Kim W, Seong KM, Youn H, Kim JW, Kim J and Youn B: Rhamnetin and cirsiliol induce radiosensitization and inhibition of epithelial-mesenchymal transition (EMT) by miR-34a-mediated suppression of Notch-1 expression in non-small cell lung cancer cell lines. J Biol Chem 288: 27343-27357, 2013.

50. Theys J, Yahyanejad S, Habets R, Span P, Dubois L, Paesmans K, Cleutjens J, Groot AJ, Schuurbiers OCJ, Lambin P, et al: High NOTCH activity induces radiation resistance in non small cell lung cancer. Radiother Oncol 108: 440-445, 2013.

51. Takebe N, Nguyen D and Yang SX: Targeting notch signaling pathway in cancer: Clinical development advances and challenges. Pharmacol Ther 141: 140-149, 2014.

52. Yuan X, Wu H, Xu H, Xiong H, Chu Q, Yu S, Wu GS and Wu K: Notch signaling: An emerging therapeutic target for cancer treatment. Cancer Lett 369: 20-27, 2015.
53. Rahman M,Deleyrolle L, Vedam-Mai V, Azari H, Abd-El-Barr M and Reynolds BA: The cancer stem cell hypothesis: Failures and pitfalls. Neurosurgery 68: 531-545, 2011

54. Reya T, Morrison SJ, Clarke MF and Weissman IL: Stem cells, cancer, and cancer stem cells. Nature 414: 105-111, 2001.

55. Lapidot T, Sirard C, Vormoor J, Murdoch B, Hoang T, CaceresCortes J, Minden M, Paterson B, Caligiuri MA and Dick JE: A cell initiating human acute myeloid leukaemia after transplantation into SCID mice. Nature 367: 645-648, 1994.

56. Al-Hajj M, Wicha MS, Benito-Hernandez A, Morrison SJ and Clarke MF: Prospective identification of tumorigenic breast cancer cells. Proc Natl Acad Sci USA 100: 3983-3988, 2003.

57. Singh SK, Clarke ID, Terasaki M, Bonn VE, Hawkins C, Squire J and Dirks PB: Identification of a cancer stem cell in human brain tumors. Cancer Res 63: 5821-5828, 2003.

58. Patrawala L, Calhoun T, Schneider-Broussard R, Li H, Bhatia B, Tang S, Reilly JG, Chandra D, Zhou J, Claypool K, et al: Highly purified $\mathrm{CD} 44^{+}$prostate cancer cells from xenograft human tumors are enriched in tumorigenic and metastatic progenitor cells. Oncogene 25: 1696-1708, 2006.

59. Li C, Heidt DG, Dalerba P, Burant CF, Zhang L, Adsay V, Wicha M, Clarke MF and Simeone DM: Identification of pancreatic cancer stem cells. Cancer Res 67: 1030-1037, 2007.

60. Eramo A, Lotti F, Sette G, Pilozzi E, Biffoni M, Di Virgilio A, Conticello C, Ruco L, Peschle C and De Maria R: Identification and expansion of the tumorigenic lung cancer stem cell population. Cell Death Differ 15: 504-514, 2008

61. Jiang F, Qiu Q, Khanna A, Todd NW, Xing L, Wang H, Liu Z, Su Y, Stass S and Katz RL: Aldehyde dehydrogenase 1 is a tumor stem cell-associated marker in lung cancer. Mol Cancer Res 7: 330-338, 2009.

62. Eyler CE and Rich JN: Survival of the fittest: Cancer stem cells in therapeutic resistance and angiogenesis. J Clin Oncol 26: 2839-2845, 2008

63. Diehn M, Cho RW, Lobo NA, Kalisky T, Dorie MJ, Kulp AN Qian D, Lam JS, Ailles LE, Wong M, et al: Association of reactive oxygen species levels and radioresistance in cancer stem cells. Nature 458: 780-783, 2009.

64. Berns A: Stem cells for lung cancer? Cell 121: 811-813, 2005

65. Kim CF, Jackson EL, Woolfenden AE, Lawrence S, Babar I, Vogel S, Crowley D, Bronson RT and Jacks T: Identification of bronchioalveolar stem cells in normal lung and lung cancer. Cell 121: 823-835, 2005

66. Huntly BJ and Gilliland DG: Leukaemia stem cells and the evolution of cancer-stem-cell research. Nat Rev Cancer 5: 311-321, 2005.

67. Krivtsov AV, Twomey D, Feng Z, Stubbs MC, Wang Y, Faber J, Levine JE, Wang J,Hahn WC, Gilliland DG, et al: Transformation from committed progenitor to leukaemia stem cell initiated by MLL-AF9. Nature 442: 818-822, 2006.

68. Mathieu J, Zhang Z, Zhou W, Wang AJ, Heddleston JM, Pinna CM, Hubaud A, Stadler B, Choi M, Bar M, et al: HIF induces human embryonic stem cell markers in cancer cells. Cancer Res 71: 4640-4652, 2011

69. Sullivan JP, Spinola M, Dodge M, Raso MG, Behrens C, Gao B, Schuster K, Shao C, Larsen JE, Sullivan LA, et al: Aldehyde dehydrogenase activity selects for lung adenocarcinoma stem cells dependent on notch signaling. Cancer Res 70: 9937-9948, 2010.

70. Hassan KA, Wang L, Korkaya H, Chen G, Maillard I, Beer DG, Kalemkerian GP and Wicha MS: Notch pathway activity identifies cells with cancer stem cell-like properties and correlates with worse survival in lung adenocarcinoma. Clin Cancer Res 19: 1972-1980, 2013

71. Zheng Y, de la Cruz CC, Sayles LC, Alleyne-Chin C, Vaka D, Knaak TD, Bigos M, Xu Y, Hoang CD, Shrager JB, et al: A rare population of CD24(+)ITGB4(+)Notch(hi) cells drives tumor propagation in NSCLC and requires Notch3 for self-renewal. Cancer Cell 24: 59-74, 2013.

This work is licensed under a Creative Commons Attribution-NonCommercial-NoDerivatives 4.0 International (CC BY-NC-ND 4.0) License. 